\title{
Egyptian legislation on the compulsory treatment of persons with psychiatric disorders: the old and the new
}

\author{
Moody Magdy Zaky MD
}

General Secretariat for Mental Health, Ministry of Health, Cairo, Egypt, email moodyzaky@me.com

\begin{abstract}
Compulsory admission to and treatment in psychiatric facilities have recently been brought into the spotlight by both psychiatrists and the media in Egypt. Interventions of this kind have always inherently involved deprivations of liberty and infringements on privacy. The debate around this issue acquired considerable heat after it was joined by the legislatures during the discussion of a Bill in Parliament. The Parliamentary Committee for Constitutional and Legislative Affairs questioned the constitutionality of the process of compulsory detention and requested more robust safeguards to protect the rights of persons with mental illness. The new Bill was passed by the Egyptian Parliament on 26 April 2009 and was due to come into force once ratified by the President and published in the Egyptian Gazette, expected in May.
\end{abstract}

\section{The old Act}

In 1944, Egypt gained its first legislation on mental health (Law 141/1944) and that Act has governed the detainment of patients affected by mental disease - it is still in effect at the time of writing and has never been amended. Detainment under the Act carries with it the possibility of compulsory admission and treatment in a psychiatric facility. Article 4 stipulates the criteria for such intervention:

Detainment may not be made of a patient affected by mental disease except in case such disease constitutes a breach of the public order or security or endangers the patient or third parties' safety.

Mental disease was defined in conformity with the once prevailing conceptualisation of mental disorder as a dichotomy between neurosis and psychosis. Only psychotic symptoms were regarded as being diagnostic of mental disease such as to allow commitment under the Act.

The Act does not specifically regulate the internment of persons who lack mental capacity, as it does not make any distinction between those who possess and those who lack mental capacity. It does not in fact address 'mental capacity' and its legal implications at all (though it does give a guardian, if there is one, the right to apply at the behest of the patient for voluntary admission and treatment). That technically means that the civil law is used to decide this particular matter. It is worth mentioning that civil law in Egypt gives the guardian a permanent power to decide on all matters on behalf of the person under guardianship.

A person can be admitted compulsorily by virtue of a written application from a person among their kin. The application has to be supported by two certificates from physicians who are not on the staff of the hospital that will detain the patient, and one of whom should be a government employee. They should attest that a mental disease that meets the criteria for compulsory admission affects the person whose detention is being requested. The physicians' certificates are valid only if less than a 10-day period has elapsed before their submission to the director of the hospital receiving the patient. (There is also a provision relating to certificates drawn up by a physician who is a relative of the hospital proprietor or director, to safeguard against any conflict of interest that might arise.)

Should the physicians find that a patient has a mental illness that meets the criteria for compulsory admission, they must order that the police detain the patient in the first instance. If detained, then the prosecuting authority or the police have the right to keep the patient under custody, and subject to medical examination by the physician, for a maximum of 24 hours from the time of apprehension. Should the physician find, after an examination, that the person does not suffer from any of the mental illnesses fulfilling the criteria for compulsory admission, they are immediately discharged.

Should the physicians have a suspicion - upon medical examination - that the person does have one of the conditions that give grounds for compulsory admission but they are unable to make a final decision on whether the condition is present or not, they must give orders to place the person under supervision at a government hospital, for a maximum of 8 days. This could be a hospital other than one allocated for mental diseases, provided that the person is subject to daily examination and at the end of the period of medical supervision the physicians make a final decision about the patient's discharge or detainment.

The 1944 Act set up a quasi-judicial body, the Control Board, to monitor and inspect all cases of compulsory admission. The director of the hospital in which a patient is subject to compulsory detention has to notify the Control Board within 3 days, in writing, about the detainment of any patient. The director also has to present a report on the case within the 4 subsequent days. Within a maximum of 30 days of the initial detainment, after studying the patient's case, the Control Board has to approve the decision to detain them further, or it could decide to discharge them.

\section{Use of the provision}

In 2006, a review of compulsory admissions registered at the Control Board in Egypt revealed that only seven had been 
registered over the period 1999-2006. This is surprisingly low, for the population of Egypt is 75 million and the country has about 13000 psychiatric beds. The number was in stark contrast to the number of compulsory admissions to psychiatric hospitals in the UK for the year 2006 - a total of 7416 (Mental Health Act Commission, 2008, p. 107).

The Egyptian findings were partially explained by the unlawful practice of hospital staff forcing patients to sign voluntary forms for admission, regardless of whether their condition met the criteria for compulsory admission or not. Hospitals also failed to report these informal admissions, as they should have done according to legal stipulations.

\section{The new Act}

In 2006, the General Secretariat for Mental Health, within the Ministry of Health, decided to review the provisions of the Act with regard to psychiatric hospitals. The General Secretariat instigated the drafting of a new Mental Health Act. Debates heated up around the criteria for compulsory admission. Some suggested there should be looser criteria for compulsory admission; these criteria would make it possible for persons with any psychiatric disorder that fulfils the criteria for admission and treatment in a psychiatric facility to be detained. Alternatively, they could be admitted if there is a possibility of further deterioration of their condition that could be averted by compulsory admission. Others advocated the tightening of criteria, restricting involuntary admission to those patients who present a serious likelihood of imminent and grave danger to themselves or others.

In 2008, a final draft of the Mental Health Act was submitted to the Egyptian Parliament for approval. The new Act distinguished between compulsory admission and compulsory treatment and established different criteria and procedures for each. Criteria and conditions for compulsory admission became very controversial during the parliamentary discussion.

Criteria for compulsory admission are now as follows:

o the existence of severe psychiatric disorder that cannot be treated unless the person is admitted to a psychiatric hospital

the person has refused such intervention voluntarily

$O$ the person presents a likelihood of grave and imminent deterioration that could be averted by such intervention; or there is a likelihood of imminent danger to the person's or to a third party's safety.

The legal process now includes notifying a judicial authority and a quasi-judicial body called the Council of Mental Health of the detention, in order to get an independent assessment within 7 days of admission. The patient's condition should be reviewed 2 days, 7 days and 1 month after their compulsory admission, as well as every month thereafter. Discharge will depend on the result of the evaluation and the patient's condition ceasing to meet the criteria for compulsory admission.

The term 'mental capacity' has been defined clearly in the new Act. Voluntary admission or treatment has been prohibited for persons who lack mental capacity unless requested by a guardian. That is, patients can be admitted voluntarily if they have mental capacity to give informed consent. If they lack this capacity, the provisions of compulsory admission, with all the safeguards connected to it, are to be applied, unless the patient has a legally appointed guardian who can apply for voluntary admission. The criteria for involuntary admission and treatment are the same for those with and without full mental capacity.

The new Mental Health Act has outlined provisions to allow a treatment order to be implemented within the community. The criteria for application include the following:

O The patient has been previously subjected to both compulsory admission and treatment.

O The patient has a history of poor adherence to medication that has contributed to the compulsory admission and treatment, on at least two occasions.

O The patient's condition is likely to deteriorate if he or she is not maintained on the proposed treatment.

The patient's condition does not meet the criteria for compulsory admission to hospital.

O The Council of Mental Health, entrusted with monitoring implementation of the law, should be notified.

O An independent assessment should be conducted before the application of such an intervention.

O The order can last for only 6 months in the first instance, but it can be renewed by the Council of Mental Health for further periods of 6 months.

Treatment orders in the community have legal force to ensure that the patient attends hospital at times determined by the treating team. Treatment orders also ensure that the treating team is able to pay visits to the patient at his or her place of residence, in pursuance of the treatment plan. If a community treatment order is breached, because the patient absconds or is non-compliant with the treatment plan, compulsory admission may be applied.

The right to integration in the community has been mentioned in the preamble of the new Act and as a part of the aftercare plan that should be made for each patient before discharge from hospital, but no provisions have been made to enforce that right.

\section{Reference}

Mental Health Act Commission (2008) Risk, Rights, and Recovery, Twelfth Biennial Report 2005-2007. TSO (The Stationery Office).

International Psychiatry is committed to the promotion of high-quality research and reporting from and about low- and middleincome countries, and cross-cultural and cross-national collaboration in the advancement of clinical science, education and advocacy in psychiatry and mental health. The original papers section of International Psychiatry is dedicated to the publication of high-quality original research and systematic reviews. Papers will be peer reviewed quickly, for publication in the next available issue of the journal, although not all papers will be accepted for publication. Articles should be no more than 1500 words, with a maximum of two tables or figures and 12 key references. Wherever possible, our expert panel of assessors will help authors to improve their papers to maximise their impact when published. Please send your submissions to ip@rcpsych.ac.uk. 